American Journal of Applied Sciences 5 (12): 1769-1772, 2008

ISSN 1546-9239

(C) 2008 Science Publications

\title{
Thermal Energy Storage in the Ground of a Greenhouse by the Polypropylene Capillary Heat Exchanger
}

\author{
${ }^{1}$ M. Lazâar, ${ }^{1}$ S. Koôli, ${ }^{1}$ M. Hazami, ${ }^{1}$ A. Farhat and ${ }^{2}$ A. Belghith \\ ${ }^{1}$ Centre de Recherches et des Technologies de l'Energie, BP 95 Hammam-Lif, Tunisia \\ ${ }^{2}$ Départment of Physics, F.S.T, The Belvedere 1002, Tunis
}

\begin{abstract}
The problem of temperature inversion is one of solar origin principal problems about which the cultures under shelters complain. Indeed, for the winter period, the temperature under greenhouse is very low at night and it is rather high during the day in summer. Consequently, the heating of the greenhouses is essential. In this work, we studied the advisability of using two exchangers coupled between them to manage thermal energy in a greenhouse. The first system is a battery of plaits with capillary tubes buried under ground with a depth of $70 \mathrm{~cm}$. The second is an air exchanger based on plastic tubes black known as agrotherms suspended with two meters and half height. The hot water, which circulates in the exchangers, is provided by the hot-water tank of the electrosolar power station of the Center of Energy Researches and Technologies (CRTEn) from Tunisia.
\end{abstract}

Key words: Solar energy, greenhouse, energy storage, capillary heat exchanger

\section{INTRODUCTION}

Our terrestrial system can absorb 3 billion tons of carbon per annum whereas we produce the double of this quantity. We will produce the triple in 30 years if the tendencies continue. Gerard Mégie, director of CNRS, point out that the carbon dioxide concentration in the atmosphere passed from 280-365 ppm (left per million) in thousand years. The principal pollutant emissions of combustion are: $\mathrm{CO}$, NO, $\mathrm{SO} 2, \mathrm{SO} 3, \mathrm{C}$ and the unburnt hydrocarbons. The carbon monoxide is the most pollutant emitted in the world, (149 million emitted ton which corresponds with $77 \%$ of the world pollutant emission. About 92.4 million tons are emitted by North America, since it is the most industrialized countries. According to the OECD (organization for the development and the economic co-operation), North America is the origin of $62 \%$ of the carbon monoxide emission, $60.6 \%$ of nitrogen oxides emission , 50.9\% of sulphur oxides emission and $66.2 \%$ of particulate matter emission in 1980. Europe is the second polluting area in the world $(31.4 \%$ of carbon monoxide emission, $32.2 \%$ of nitrogen oxides emission, $43.8 \%$ of sulphur oxides emission and $28.8 \%$ of particulate matter emission).

The massive combustion of the fossil fuels and the biomass is at the origin of a strong production of carbon dioxide (CO2) which is responsible for an increase of greenhouse gas production.

This last conduit to a progressive climatic reheating which will lead to changes of balance (turnings into a desert, floods...).

The modern greenhouses are large consumers of energy, mainly in the form of heat. Indeed, thermal energy can represent, in traditional installations, from $15-25 \%$ of the production costs ${ }^{[1]}$. In France (1993), according to the agency of the environment and control of energy A.D.E.M.E, the heating of the agricultural greenhouses consumes $3 \%$ of the electric power and $11 \%$ of fossil energies. This type of energy is responsible on the increase in the greenhouse effect, air pollution, pollution of the grounds, of water, acid rains. Moreover the stock of fossil energies is limited to one century for the gas and oil and to two centuries for coal. Reducing fossil consumption will make it possible to prolong their use and to reduce the heating loads. Thereafter the storage of the excess of energy under the greenhouse is the best solution. Different recuperation systems of solar energy and its storage were tested. The systems used were; the changing-phase materials ${ }^{[2]}$, the water accumulators ${ }^{[3]}$ and the ground. Some authors used a direct storage of the heat air into the greenhouse ground. This system consisted of an air extractor coupled with buried PVC exchangers. They saved 12\% of annual heating energy. But they underlined the insufficiency of data concerning geometry, necessary depth and thermal insulation to optimize the dimensions of their system. Some researchers showed that it is necessary to put the buried exchangers close to the ground surface to increase the storage and the direct energy restitution and to minimize the losses towards the deep ground. Other researchers ${ }^{[3]}$ carried out energy storage in water accumulator. Then, an immersed exchanger was used to ensure the heat transfer between the greenhouse air and the accumulator. They reached an efficiency of $22 \%$, but this system is more expensive than direct storage in the ground. Boulard and Baille ${ }^{[4]}$ simulated and analyzed the influences of some parameters on the performances of two thermal energy storage systems. These systems using PVC exchangers were; air-ground and waterground system. These authors show that the heat storage by the air-ground system, called direct storage, was twice as significant as that stored by the water-ground system called indirect storage. They quantified the maximum daily heat quantity extracted in the first case of $40 \mathrm{Wm}^{-2}$. In spite of their diversity, these conditioning systems cannot ensure the autonomy of the traditional plastic tunnels for which the requirements in heating are significant. 
Am. J. Applied Sci., 5 (12): 1769-1772, 2008

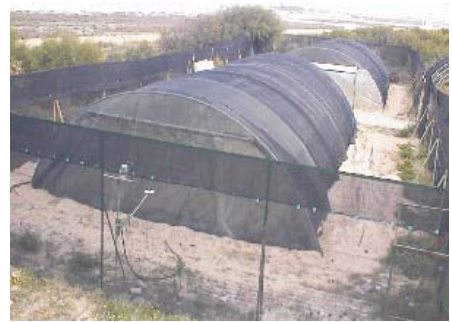

Fig. 1: The tow experimental greenhouses

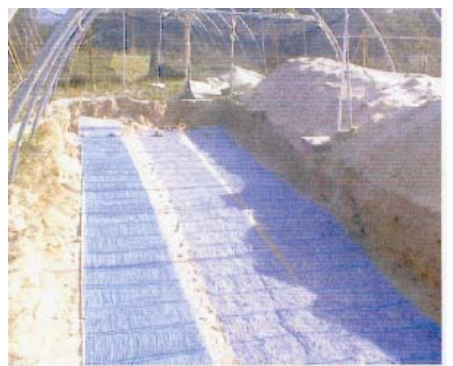

Fig. 2: Capillary heat exchanger burred in the soil of the greenhouse

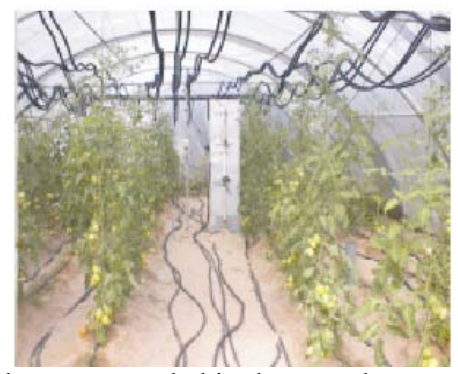

Fig. 3: Agrotherm suspended in the greenhouse

This article describes the use of capillary polypropylene heat exchanger for a tunnel greenhouse conditioning. In

Laboratory of Energetic and the Thermal Processes (LEPT) of the Center of Energy Technologies and Researches from Tunisia, we installed two agricultural greenhouses (Fig. 1) of the same surface $\left(100 \mathrm{~m}^{2}\right)$. One greenhouse is equipped with a heating system and the other not. The last is useful like a pilot greenhouse. Two exchangers coupled between them to manage thermal energy in a greenhouse compose the heating system used. The first system is a battery of plaits with capillary tubes buried under ground with a depth of $70 \mathrm{~cm}$ (Fig. 2). The second system is an air exchanger based on plastic black tubes known as agrotherms suspended with two meters and half height. This exchanger is always used for the greenhouse heating by the geothermic (Fig. 3). These two exchangers are coupled to ensure the autonomous greenhouse air-conditioning. We provide the exchanger in hot water by the hot water tank of the electro-solar power station of our laboratory. We feed the heating system by water at a temperature of $50^{\circ} \mathrm{C}$.

During three days, we follow the change of the air temperature inside the greenhouse, the relative humidity, the heat flow in the ground and the soil temperature at a various depths. To study the climate behaviour in the greenhouse in the presence of a heating system, it should be compared with that of a greenhouse without heating system for that we need another pilot greenhouse.

\section{MATERIALS AND METHODS}

Measurement of the temperatures in the soil were made with thermocouples connected with numerical voltage setting, which were placed on the soil surface and at the different depth from 10-70 cm within soil, in the middle of the greenhouse. The average temperature of the soil is measured by a TCAV Averaging soil Thermocouple Probe which, parallels 4 thermocouple junctions into one. One channel is required to measure the output voltage which represents the average temperature of the four junctions. The TCAV is most often used to obtain the average temperature of a soil layer for use in calculating stored energy. It's constructed with type E thermocouple wire (chromel-constantan).

The ambient temperatures were measured with 107 temperature probe witch use thermistors to measure temperature. A 41301 radiation shield is used to mount the 107 probe and limit solar radiation loading of the 107 . The measurement rang of this probe is between -35 and $+50^{\circ} \mathrm{C}$. The thermistor inter-changeability error is loss than $\pm 0.2^{\circ} \mathrm{C}$ over $0-60^{\circ} \mathrm{C}$ and $\pm 0.4^{\circ} \mathrm{C}$ with $-35^{\circ} \mathrm{C}$. The black outer jacket of the cable is Santoprene rubber. This compound was chosen for its resistance to temperature extremes moisture and UV degradation. However this jacket will support combustion in air.

For the velocity measurement of the wind, a revolving vane anemometer of three tronic cups was installed. In the range of measurement ranging between 0.45 and $45 \mathrm{~m} \mathrm{sec}^{-1}$ the precision of this sensor is $1.5 \%$. Solar radiation was measured with a pyranometer. The precision of this last is approximately $5 \%$.

To measure the soil heat flux a HFT-3 soil heat flux plate was used. The location of the two heat flux plates/thermocouples should be chosen to be representative of the area under study. The plates are buried at a fixed depth of between 5 and $8 \mathrm{~cm}$ to reduce errors due to vapour transport of heat.

The relative humidity of air is measured by a HMP35C probe. The relative humidity measurement range is from 0 to $100 \%$. The operating temperature is between -20 and $60^{\circ} \mathrm{C}$.

The soil moisture is measured by a 227 gypsum soil moisture blocks. This instrument provides a convenient method for estimating soil water potential. All these probes are connected to a datalogger Campbell $21 \mathrm{X}$ which makes an instantaneous acquisition every $30 \mathrm{sec}$ and records the values realised by $10 \mathrm{~min}$ step.

Characterization of the microclimate under greenhouse without heating system: Evolution of the internal and external air temperature under greenhouse without energy storage system: The evolution of the interior and exterior greenhouse climate allows studying the answers of the greenhouse according to the weather conditions. Figure 4 shows the variation curve of the internal temperature (Tai) and external (Tae) in April. The results permit to note that: 


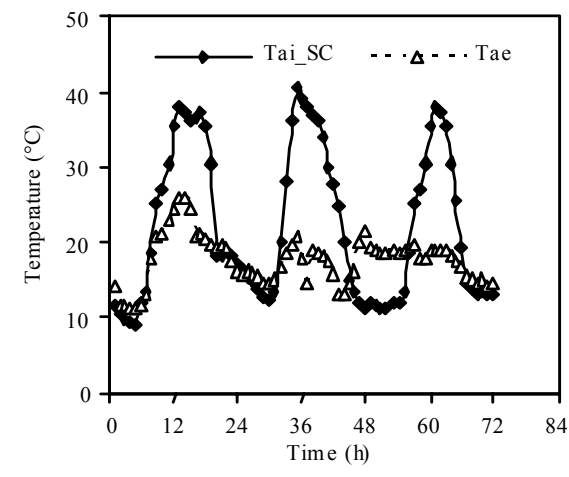

Fig. 4: Evolution of the interior and exterior air temperature under greenhouse without heating system (07-09 April 2005)

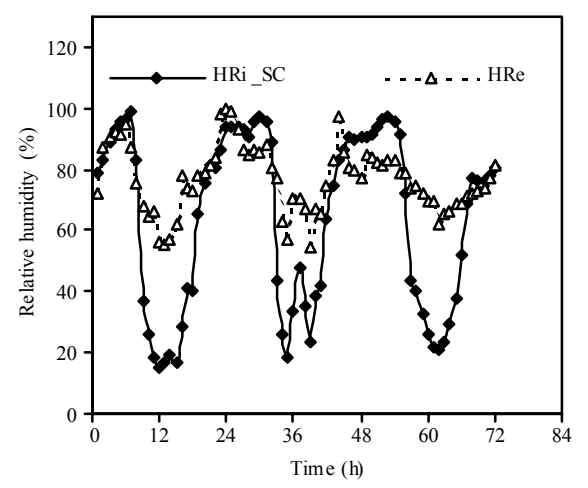

Fig. 5: Evolution of the relative humidity inside and outside the greenhouse without heating system (07-09 April 2005)

- At night, the energy losses by infra-red emission towards the sky involve the fall in the temperature of the air, often more marked inside than outside; this is the inversion of the temperature phenomenon. As an example, in April $(07 / 04 / 05)$, Tai $=8^{\circ} \mathrm{C}$ and Tae $=13^{\circ} \mathrm{C}$ (Fig. 4). This phenomenon was observed by several researchers, in particular by Hassani et al. (1989) with this same type of greenhouse

- In the day, the combined effects of the trapping of the solar radiation and the reduction of the convective exchanges inside the greenhouse lead to the rise in the greenhouse temperature which reaches relatively high values (about $40^{\circ} \mathrm{C}$ )

Evolution of the relative humidity inside and the outside of the greenhouse: Figure 5 shows the evolution of the relative humidity inside and outside the greenhouse according to time, it is noted that:

- At night, the relative humidity of the interior air is very high, it is about $100 \%$. This is with the phenomenon of condensation which occurs on the walls of the greenhouse

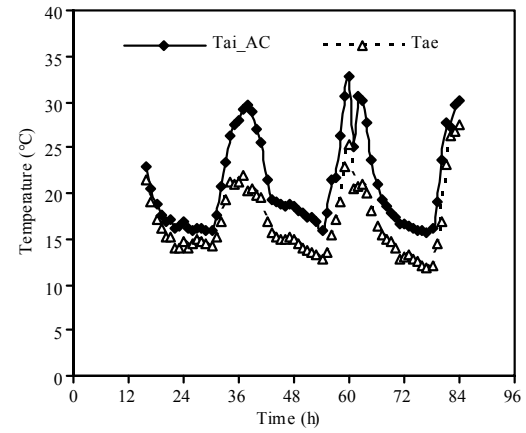

Fig. 6: Evolution of the interior (Tai_AC) and exterior (Tae) air temperature under greenhouse with heating system (07-09 April 2005)

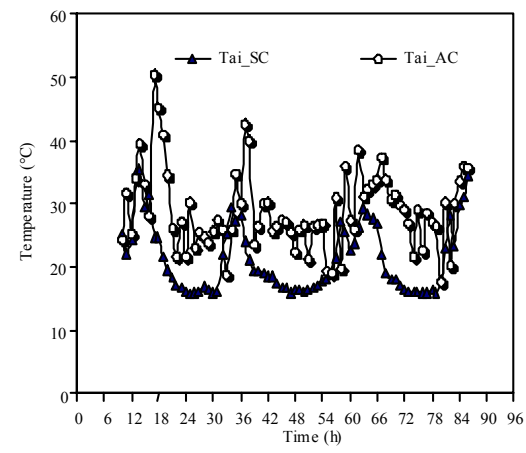

Fig. 7: Evolution of the interior air temperature under greenhouse with (AC) and without (SC) heating system (25-28 April 2006)

- During the day, the rise in the interior air temperature influences directly the interior relative moisture. Indeed, we note an exaggerated lowering of the moisture which can reach the $20 \%$

Characterization of the microclimate under greenhouse in the presence of a heating system: Using the hot water loop of the electro-solar power station of the Center of Energy Technologies and researches (CRTEn), we heated the greenhouse at a temperature of $50^{\circ} \mathrm{C}$. The two suspended and buried heating systems function at the same time. We show in Fig. 6 the air temperature change inside and outside the greenhouse in the presence of the heating system. The heating lasted three days successive (15-16-17/04/2005). We notice that the temperature of the interior air is always higher than that of the surrounding air. The phenomenon of inversion of temperature misses.

In Fig. 7 the air temperature change inside the greenhouse without (SC) and with (AS) a heating system. We notice that the difference between the diurnal and nocturnal air temperature is attenuated. Indeed, in presence of heating system, the air temperature during the day is higher than the air temperature of the greenhouse without heating system. During the night, the air temperature under the greenhouse using heating system is higher than that of the greenhouse 
Am. J. Applied Sci., 5 (12): 1769-1772, 2008

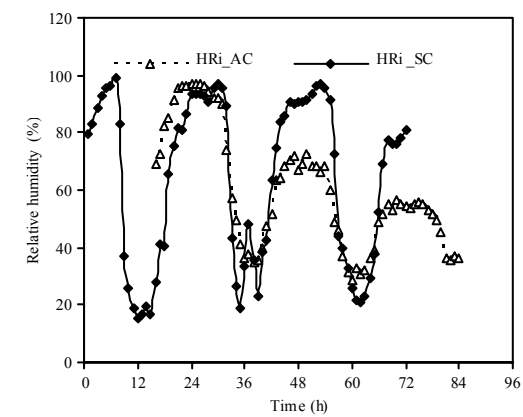

Fig. 8: Evolution of the relative humidity inside and outside the greenhouse with (AC) and without (SC) heating system (07-09 April 2005)

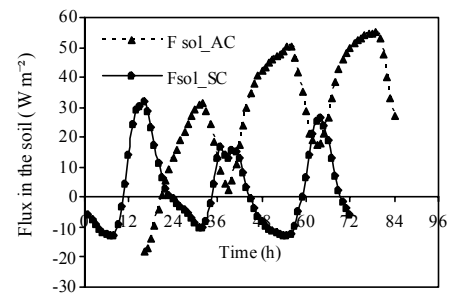

Fig. 9: Evolution of the soil heat flux with (AC) and without (SC) heating system (07-09 April 2005)

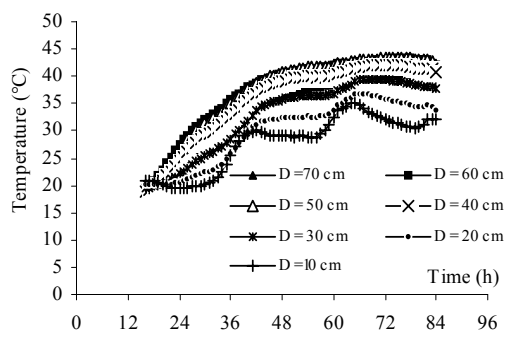

Fig. 10: Evolution of the soil temperature at different depth (D from 10 to $70 \mathrm{~cm}$ ) (07-09 April 2005)

without heating system. At night, the heating contribution compensated for the defect of heat by the losses by infra-red emission towards the sky, consequently the air temperature increases.

Figure 8 shows the variation of the air relative humidity inside the two greenhouses. This curve shows that in presence of a suspended and buried heating system, the relative humidity becomes less significant during the day $(65 \%)$ and higher during the night $(30 \%)$ if we compare it with a greenhouse not equipped with heating system.

Figure 9 shows the variation of the heat flow in the ground for the two greenhouses. Without heating system, the heat flow in the ground is sometimes negative sometimes positive. Indeed during the day, the ground gains solar energy. The heat flow is thus counted positively. It is the period of energy storage. The energy quantity per day which the ground can recover differs from one season to another; all depends on the external climate and in particular on the sunning. During the night, the heat flow exchanged with the ground is negative. It corresponds to an energy loss. The ground is in stage of destocking. For the greenhouse equipped by a heating system, the ground stores heat in excess. Heat flow is always positive. When the heat flow is maximal for the greenhouse equipped with a heating system, the heat flow of the pilot greenhouse is minimal and conversely.

In Fig. 10, we show the variation of the soil temperature in different depths (from 10-70 cm). We notice that the ground temperature evolution for depths equal to 10,20 and $30 \mathrm{~cm}$ is random. This zone is influenced by the heating systems and by the direct radiations. This zone is a zone of transition; it's not useful like an energy storage section. Consequently, the zone, which can be useful for thermal energy storage, is of depth beyond $30 \mathrm{~cm}$.

\section{CONCLUSION}

The use of a heating system for the agricultural greenhouses is a very judicious choice. Indeed, this heating system eliminates the temperature inversion phenomenon and decreases the excessive variation of relative humidity of the air between the day and the night. The change of the temperature in the ground with various depths ensures that the zone which can be useful for thermal energy storage in the ground is of depth beyond $30 \mathrm{~cm}$. This system is not harmful with the environment since the conventional sources of energy are not used. It's also economic since it ensures an autonomous heating of the greenhouse for four months of the cold period of the year (January-April). For the rest of the period (November-December) we must use an auxiliary heating system ${ }^{[5]}$.

\section{REFERENCES}

1. Kittas, C., T. Boulard and G. Papadakis, 1997. Natural ventilation of a greenhouse with ridge and side openings: Sensitivity taux temperature and wind effect. Trans. ASAE, 40: 415-425.

2. Takukar, T. and H. Nishina, 1981. A solar greenhouse with phase change energy storage and a microcomputer control system. Acta Hortic., 115.

3. Lachal, B. and P. Hollmuler, 1996. Université de Genève: Stockage de chaleur, gestion de l'énergie et du climat dans les serres horticoles. Revue Suisse, vatic. Arboric. Hortic., 28: 215-218.

4. Boulard, T. and A. Baille, 1986. Simulation and analysis of soil heat storage systems for a solar greenhouse. II. Simulation. Energy Agric., 5: 285-293.

5. Lazâar, M., S. Kooli, M. Hazami, A. Farhat and A. Belghith, 2004. Comparison between a solar system and a fuel boiler for greenhouse air-conditioning. Desalination, 168: 391-396. 